\title{
ə Biodegradability of Polyvinyl Alcohol Based Film Used for Liquid Detergent Capsules
}

Questions and potential misperceptions have arisen about the potential contribution of liquid detergent capsules to the environmental microplastics issue. The film of these detergents is highly water soluble, also in cold water, as it must fully dissolve during every type of washing process. Water-soluble grades of polyvinyl alcohol, the most commonly used detergent capsule film material, are recognised to be biodegradable. In the current paper, adequate biodegradability is confirmed by means of ready biodegradation screening tests, across a range of polyvinyl alcohol detergent grade films. The high water solubility in itself implies that detergent capsule films are not within the microplastic scope. Furthermore, their biodegradability ensures there is no concern for persistence or accumulation in the environment.

Key words: Polyvinyl alcohol, Soluble film, Liquid detergent capsules, Biodegradation, OECD biodegradability screening test

\begin{abstract}
Biologische Abbaubarkeit der für Flüssigwaschmittelkapseln verwendeten Folie auf Polyvinylalkoholbasis. Über den potenziellen Beitrag von Flüssigwaschmittelkapseln zur Mikroplastikproblematik in der Umwelt sind Fragen und mögliche Fehleinschätzungen aufgekommen. Die für Waschmittelkapseln verwendete Folie ist gut wasserlöslich, auch in kaltem Wasser, da sie sich in allen Waschprozessen vollständig auflösen muss. Wasserlösliche Polyvinylalkohole werden am häufigsten als Filmmaterial für Waschmittelkapseln verwendet und sind als biologisch abbaubar bekannt. In der vorliegenden Arbeit wird die ausreichende biologische Abbaubarkeit durch OECD ScreeningTests zur biologischen Abbaubarkeit für eine Reihe von Polyvinylalkohol-Waschmittelfolien bestätigt. Die gute Wasserlöslichkeit an sich impliziert, dass Waschmittelkapsel-Folien nicht in den Bereich des Mikroplastiks fallen. Darüber hinaus stellt ihre biologische Abbaubarkeit sicher, dass Bedenken hinsichtlich Persistenz oder Akkumulation in der Umwelt unbegründet sind.
\end{abstract}

Stichwörter: Polyvinylalkohol, Lösliche Folie, Flüssigwaschmittelkapseln, Biologischer Abbau, OECD-Test zur biologischen Abbaubarkeit
1 Introduction

\subsection{Microplastic concerns}

The unintentional release of microplastic into the aquatic environment (marine as well as freshwater) is of concern for human health and the ecosystem [1]. 'Microplastic' refers to microscopic solid particles (i.e. not water soluble) made of a synthetic polymer, with a high resistance to biodegradation. In the environment, progressive physical fragmentation into smaller and smaller particles can take place. Such particles are readily available for ingestion and are potentially liable to transfer within food chains. Further, microplastics are practically impossible to remove from the environment after release. These properties are known to result in exposure to a wide range of organisms including invertebrates, fish, marine reptiles, birds and cetaceans (either directly or via trophic transfer) and may also result in exposure to humans via food or water.

The definition of microplastic has been extensively assessed and discussed in Europe due to the proposed restriction of use of intentionally added microplastic in the European Economic Area. The European Commission initially defined microplastic as: 'synthetic water-insoluble polymers of $5 \mathrm{~mm}$ or less in any dimension' (EU Commission [2]). Subsequently, this definition was refined by the European Chemicals Agency: 'polymers that are (bio)degradable [are excluded]' (ECHA [1]); and latterly by ECHA's Committee for Risk Assessment: '[The term microplastic] means particles containing solid polymer, to which additives or other substances may have been added, and where $\geq 1 \% \mathrm{w} / \mathrm{w}$ of particles have (i) all dimensions $\leq 5 \mathrm{~mm}$, or (ii) a length of $\leq 15 \mathrm{~mm}$ and length to diameter ratio of $>3$... [this term] shall not apply to polymers that are (bio)degradable ... with a water solubility $>2 \mathrm{~g} / \mathrm{l}$ (ECHA RAC [3]). According to this definition the water-soluble film used for liquid detergent capsules is not a microplastic. This is because the film size is outside of the microplastic range, and the film is both water-soluble and biodegradable - as further outlined in this paper.

Nevertheless, misperceptions do exist. For example, Thompson [4] incorrectly implies that polyvinyl alcohol (PVOH) from laundry detergent pods would be a common component in microplastic debris found in the environment. Thompson [4] sources its information from GESAMP [5], which in turn refers to Hidalgo-Ruz et al. [6] and to Vianello et al. [7]. The literature review by Hidalgo-Ruz et al. [6] indeed reports 3 earlier studies (out of a total of 42) in which

\footnotetext{
Boeije Consulting, Sint-Martens-Latem, Belgium

McBride Manchester UK

Reckitt Benckiser, Heidelberg, Germany

Unilever, Rotterdam, The Netherlands

Henkel, Düsseldorf, Germany

Kuraray, Merrillville, USA

Procter \& Gamble, Strombeek-Bever, Belgium
} 
PVOH was identified among sorted microplastic debris. However, the considered studies all predate the market entry of liquid laundry detergent capsules - which mainly occurred after 2010. Vianello et al. [7] sampled ten sites in the Venice Lagoon (Italy), and found PVOH in only one specific location, which was an industrial discharge. Claessens et al. [8] investigated microplastic in marine sediment near the Belgian coast. This study identified $\mathrm{PVOH}$ in fibres, and concluded that this was most likely originating from fishing lines. Microplastic films were also found, but all identified to be made of nylon.

In conclusion, the available literature does not indicate an association of $\mathrm{PVOH}$ film from detergent capsules with environmental microplastic. Nevertheless, it also shows that traces of PVOH from other sources can indeed be found in the marine environment. It is important to note that $\mathrm{PVOH}$ has many, very different applications. The overarching nomenclature of PVOH covers a broad variety of polymer designs - several of which do not exhibit the same water solubility and biodegradability as the $\mathrm{PVOH}$ grades used for detergent film applications. Thus, it is not surprising that such materials may indeed persist sufficiently long in the environment to be detectable.

Only a specific range of $\mathrm{PVOH}$ meets the performance requirements to be usable for detergent soluble film applications. Hence, it is crucial to have a sufficiently accurate and narrow identification of the PVOH polymer characteristics to assess the environmental fate profile of detergent film material. The objective of the current paper is to review the biodegradability of $\mathrm{PVOH}$ film that is used in detergent capsules, and to assess whether these materials may pose a risk for persistence in the environment. In addition, the paper aims to explore whether these films may be contributing to microplastic in the environment.

\subsection{Detergent capsules}

Detergent capsules are a fairly recent innovation in the laundry and home care sector. In this highly concentrated product form, all active ingredients are contained in a single unit dose capsule. This capsule dissolves after contact with water inside the washing machine or dishwasher, and then releases the detergent. This way, consumers can easily dose the correct amount of product without the need to measure, and without spills that may occur when dispensing a traditional free-flowing detergent product. In addition, the high level of concentration leads to lower product amounts.

The capsule material is made of a water-soluble film. This is generally based on $\mathrm{PVOH}$, with polymer backbone modifications and specific performance additives. The films are developed such that they readily dissolve as intended in the washing process, including in cold water cycles. To avoid spillage and to ensure consumer safety, the soluble film is designed not to dissolve and rupture prematurely (e.g. when touched with wet hands, or when put into the mouth); to resist compression (e. g. when squeezed by a child); and to trigger an aversive reaction in case of oral contact. These features are required for liquid laundry detergent capsules in the EU under regulation (EU)1297/ 2014 (amending the CLP Regulation (EC)1272/2008), and are also included the voluntary ASTM Standard for this product category [9].

\subsection{Polyvinyl alcohol}

$\mathrm{PVOH}$ is a synthetic resin that is generally prepared by the saponification (hydrolysis) of polyvinyl acetate (Finch [10]). When all acetate groups have been converted to alcohol groups, 'fully hydrolysed' PVOH is obtained. On the other hand if a certain proportion of acetate groups are allowed to remain, the result is referred to as 'partially hydrolysed' PVOH (Figure 1). While in fact a vinyl alcohol - vinyl acetate copolymer, the latter is nevertheless also commonly referred to as PVOH.

$\mathrm{PVOH}$ has a wide variety of applications. It is a key ingredient in formulation processes in various industries including food packaging, construction, electronics, coatings, printing, textile, cosmetics, and paper. Demand is mainly driven by the food packaging industry, which accounted for $31.4 \%$ of the global volume in 2016 (Grand View Research [11]). PVOH is also extensively used in the construction industry as auxiliary component in cement-based composite materials (Thong et al. [12]). Other applications are in warp sizing and processing of textile fibres, in paper manufacturing (e. g. coating to make the paper more resilient to oils and grease), and in adhesives (Finch [10]). Muppalaneni and Omidian [13] provide an overview of medical and pharmaceutical applications, such as tablets and contact lenses, and surgical threads (Gaaz et al. [14]). PVOH is also used in sports fishing: $\mathrm{PVOH}$ bags filled with oil-based or dry fishing bait are attached to the hook, and as PVOH is soluble in water, when the bag lands on the bottom it leaves the hook bait surrounded by pellets and ground bait that attracts fish (American Carp Society [15]).

The wide diversity of applications of PVOH implies there is also a broad range of required physical-chemical characteristics, depending on the specific use. This is partially achieved by selecting an optimal polymer size and balance between vinyl acetate and vinyl alcohol in the copolymer. Further, it is achieved by means of modifications of the polymer backbone and by means of additives (e.g. plasticisers) that are blended into the resin. Different polymer modifications are described in Monosol [16], e.g. inclusion of an anionic monomer unit in the copolymer, or by having a carboxyl group modified copolymer. Consequently, when assessing $\mathrm{PVOH}$ used in detergent capsule applications, it is essential to focus on material with characteristics that are suitable for this specific application. Most importantly, as outlined above, $\mathrm{PVOH}$ used in a detergent film requires excellent solubility in cold water.

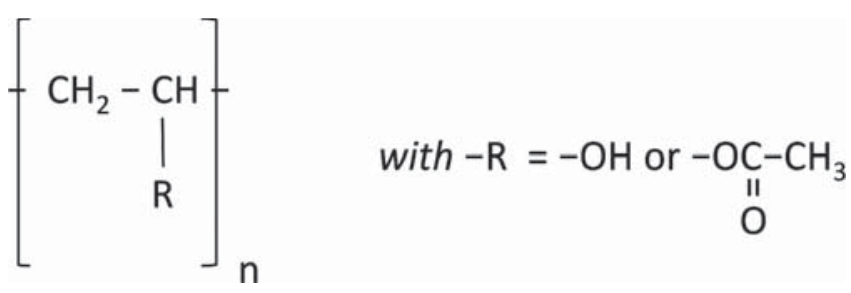

Figure 1 Chemical structure of PVOH (partially hydrolysed) 


\subsection{Water solubility of $\mathrm{PVOH}$}

The water solubility of PVOH depends mainly on its degree of hydrolysis $(\mathrm{DH})$, and to a second extent on its degree of polymerization (DP) (Finch [10]). This is determined by two counteracting influences of the hydroxyl groups. On the one hand, the many hydroxyl groups cause $\mathrm{PVOH}$ to have a high affinity to water, which drives water solubility. On the other hand, the strong hydrogen bonding between inter- and intramolecular hydroxyl groups can greatly impede solubility in water. As a consequence, fully hydrolysed $\mathrm{PVOH}$ is highly crystalline and only dissolves in hot water $\left(>60^{\circ} \mathrm{C}\right)$, whereas 'partially hydrolysed' $\mathrm{PVOH}$ is more weakly hydrogenbonded, less crystalline, and generally soluble in cold water $\left(<10^{\circ} \mathrm{C}\right)$ (Monosol [16]). Finch [10] shows high water solubility at ambient temperature $\left(20^{\circ} \mathrm{C}\right)$ for $\mathrm{PVOH}$ with a degree of hydrolysis up to $90 \%$, but rapidly dropping with further increasing $\mathrm{DH}$. The observed negative effect of an increasing degree of polymerization (in the range of 500 2500) on solubility was of limited relevance for PVOH with a degree of hydrolysis $<90 \%$. This is illustrated in Figure 2 for a degree of polymerisation of 1750 (after Finch [10]). Note that for practical detergent applications, $\mathrm{PVOH}$ films are modified and contain additives, to ensure that they are $100 \%$ soluble in cold water (as opposed to what is shown in Figure 2 for pure unmodified PVOH).

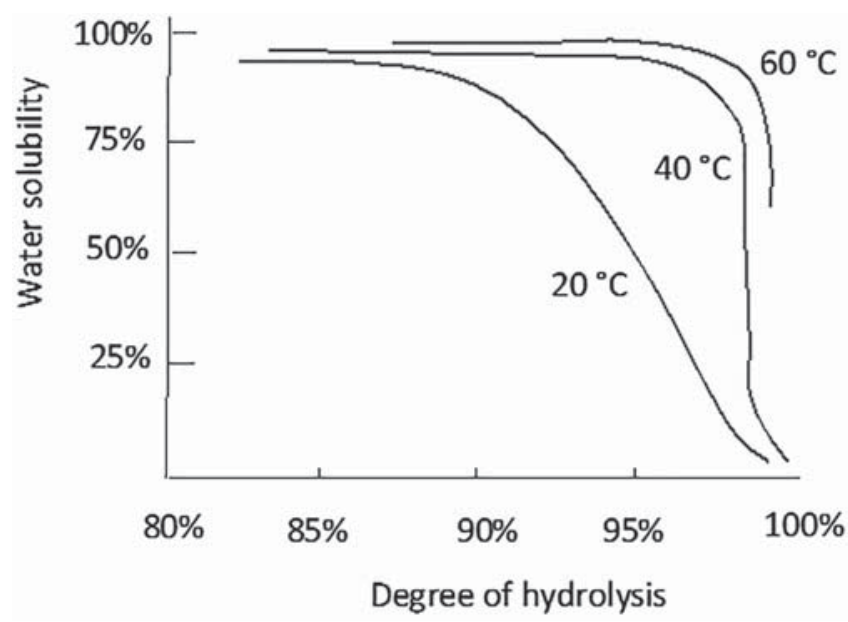

Figure $2 \mathrm{PVOH}$ water solubility as a function of $\mathrm{DH}$ and temperature

Similarly, Amann and Minge [17] report that an optimum cold water solubility can be observed with a degree of hydrolysis of $87 \%-89 \%$ for a degree of polymerisation between 600 and 2400, whereas a totally hydrolysed $\mathrm{PVOH}$ is almost insoluble in cold water and can only be dissolved by boiling in water for an extended period of time. Julinová et al. [18] confirm that the solubility of $\mathrm{PVOH}$ is highly reliant on the degree of hydrolysis: products with $\mathrm{DH}=95 \%$ are insoluble in cold water and only dissolve at $65^{\circ} \mathrm{C}-70^{\circ} \mathrm{C}$; whereas when $\mathrm{DH}=88 \%$, the PVOH is highly soluble in cold water. When $\mathrm{DH}$ drops below circa $80 \%$, the trend is reversed. With $\mathrm{DH}$ between $70 \%$ and $80 \%$, precipitation of $\mathrm{PVOH}$ from the solution occurs at temperatures below $35^{\circ} \mathrm{C}$, and $\mathrm{PVOH}$ with a content of acetate groups more than $50 \%$ becomes insoluble in water.

\subsection{Biodegradability of $\mathrm{PVOH}$}

$\mathrm{PVOH}$ is recognised as one of the very few vinyl polymers soluble in water that is susceptible to ultimate biodegradation in the presence of suitably acclimated microorganisms. Chiellini et al. [19] provide a comprehensive overview of the biodegradability of PVOH. More recent reviews are presented in Kawai and $\mathrm{Hu}$ [20] and in Amann and Minge [17]. Chiellini et al. [19] conclude that the ultimate biological fate of PVOH depends largely upon the environment it reaches. High levels of biodegradation were observed in aqueous environments that contained acclimated bacterial species often associated with PVOH-contaminated waste water and sewage sludge. Similarly, Julinova et al. [18] state that in prior research, PVOH-degrading bacteria had been isolated from settings previously contaminated by $\mathrm{PVOH}$, where adaptation could take place. However, from this, these authors deduce that in uncontaminated environments adapted bacteria may not be present, and conclude that PVOH is essentially non-biodegradable. They also mention that in many cases, PVOH passes through waste water treatment plants unchanged - although this is not substantiated, because the references provided describe research with a different material: poly(vinylpyrrolidone), not PVOH. Due to the broad down-the-drain emission of $\mathrm{PVOH}$ used in liquid detergent capsules (following wide dispersive consumer use), there is a steady load of PVOH into the domestic waste water pathway. As such, it is fair to assume that acclimation has taken place in sewage treatment activated sludge, or in the receiving environment in case of untreated emissions. Thus, the conclusions by Chiellini et al. [19] apply in this context.

Like a majority of polymers (e.g. polyolefins, polystyrenes and polyacrylates), $\mathrm{PVOH}$ has a carbon-carbon single bond backbone. However, unique among synthetic polymers, $\mathrm{PVOH}$ also exhibits a 1,3-diol structure that is quite common in natural materials such as carbohydrates. Unsurprisingly, as a general mechanism, the biodegradation of $\mathrm{PVOH}$ starts on the outside of the cells via enzymatic attack on these 1,3-diol repeating units. This results in a mixture of acetoxy-hydroxy and hydroxy fatty acids. Upon intracellular enzymatic de-acetylation, these can be further metabolised via the classical $\beta$-oxidation pathway and Krebs cycle. This mechanism is common to all PVOH-degrading microorganisms (Solaro et al. [21]). Among the degrading strains, many species can be found in the genus Pseudomonas and Sphingomonas (Yamamatsu et al. [22]). A simplified illustration of the proposed PVOH biodegradation pathway is given in Wilkes and Aristilde [23] (Figure 3).

In aqueous aerobic environments, biodegradation of PVOH runs parallel with its water solubility (Chiellini et al. [24]). Kawai and $\mathrm{Hu}$ [20] report that the biodegradation of $\mathrm{PVOH}$ is affected by chemical structural characteristics, such as stereotacticity and 1,2-diol units. It was not found to be significantly influenced by the DP when this was in the range of 10-2000 (which implies the DP is not a driving factor for PVOH used in detergent capsule films). The effect of the DH is not entirely clear. DH was not found to have a substantial impact when above $80 \%$ while below a level impeding solubility (several references quoted in Chiellini et al. [19]). Hatanaka et al. [25] saw a reduction of biodegradation activity as the DH lowered. Chiellini et al. [26] observed a 
<smiles>CC(C(O)CC(O)CC(C)(C)C)C(O)CC(C)(C)C</smiles><smiles>CCC(O)CC(=O)CC(O)CC(O)CC</smiles><smiles>CCC(O)CC(=O)CC(=O)CC(O)CC</smiles><smiles>CCCOCOO</smiles>

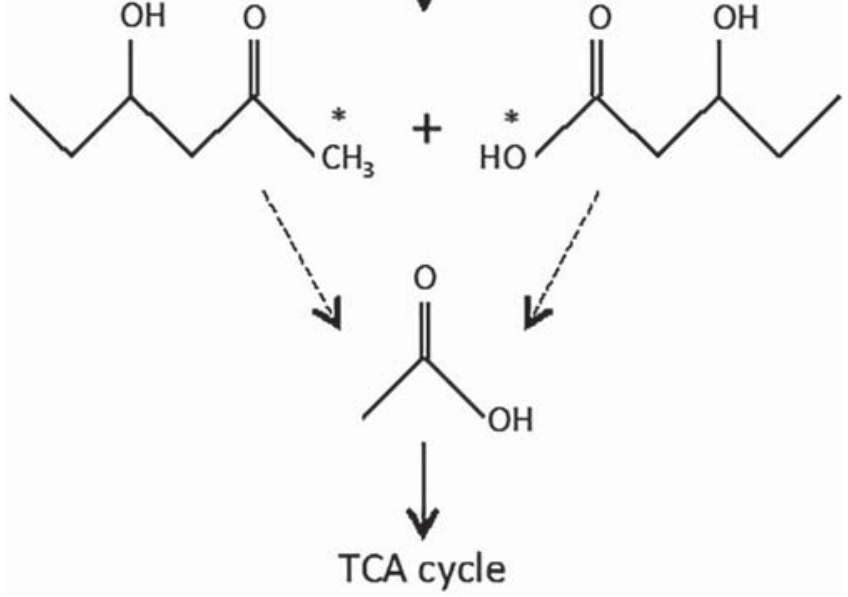

Figure 3 Proposed PVOH biodegradation pathway (after Wilkes and Aristilde [23])

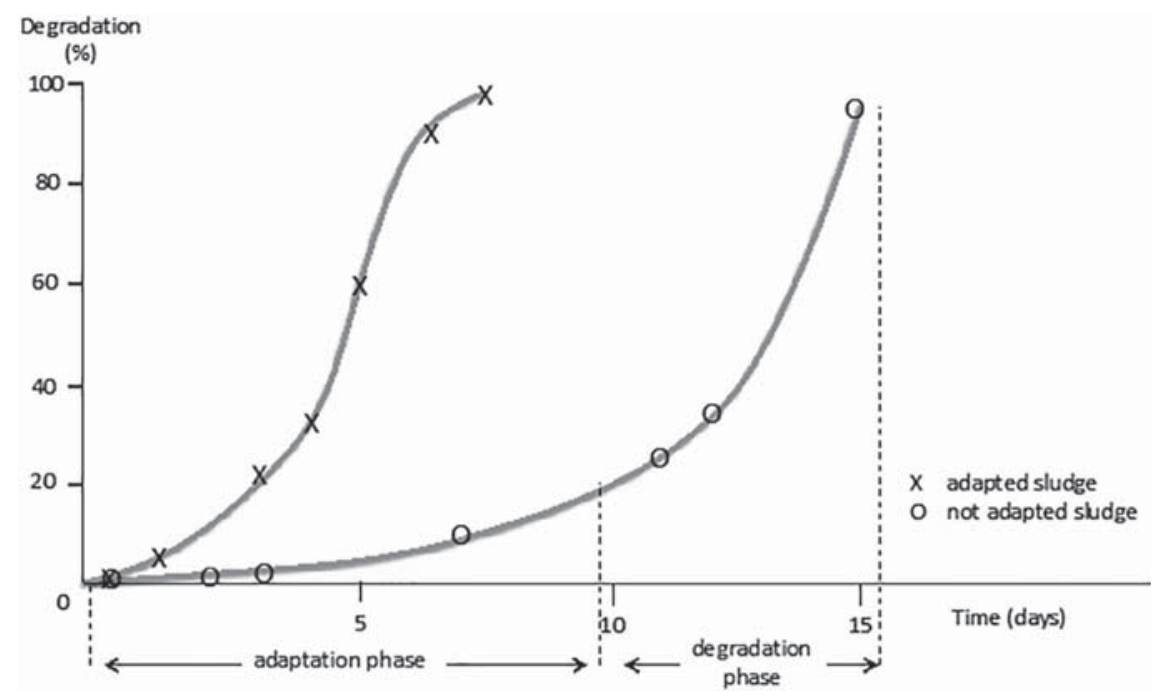

Figure 4 Example of sludge adaptation for $\mathrm{PVOH}$ in the OECD 302B test similar extent of biodegradation with $\mathrm{DH}=72 \%, 88 \%$ and $98 \%$, but the lag phase with the $\mathrm{DH}=72 \%$ material lasted 10 days longer than with the other materials.

Studies conducted with cultures or environmental inoculums that had not been previously exposed to PVOH tended to result in fairly slow degradation rates. On the other hand, for example in presence of sludge taken from a paper mill wastewater treatment system (well-adapted to PVOH), the degradation of $\mathrm{PVOH}$ proceeded at comparable rates as for cellulose (Pajak et al. [27]). Hence, adaptation of the microbial community was found to have a favourable impact on the biodegradation rate of PVOH. The effect of adaptation is also illustrated in the guidelines for the OECD 302B (Zahn-Wellens/EMPA test) [28]. In this guideline document, $\mathrm{PVOH}$ is used as an example of a substance that exhibits an adaptation phase followed by a degradation phase in the test. In this particular example (Figure 4), near-complete biodegradation was reached both with adapted and non-adapted sludge, but without prior adaptation the process took about twice as long. This illustrates well that also without prior acclimation to PVOH, microbial communities will eventually be able to degrade this material. In this context, it should be noted that for widely used consumer products, such as detergents, there is a fairly constant and ongoing emission (rather than isolated peak exposures). Consequently, the microbial communities in the receiving environment and waste water treatment plants are generally well-adapted to the ingredients.

Matsumura et al. [29] demonstrated biodegradability of $\mathrm{PVOH}$ under anaerobic conditions, using anaerobic river sediments and anaerobically treated activated sludge from a sewage treatment plant. Marušincová et al. [30] found that $\mathrm{PVOH}$ was biodegraded under denitrifying conditions with a microbial community that originated from a municipal wastewater treatment plant. The derived microbial consortium was capable of PVOH degradation under both denitrifying and aerobic conditions.

Chiellini et al. [31] investigated the rates and extents of absorption and desorption of PVOH on different solid substrates. PVOH with a higher degree of hydrolysis was more adsorbed, whereas an increase in molecular weight decreased adsorption. Biodegradation experiments carried out in liquid cultures of $\mathrm{PVOH}$ that were adsorbed on montmorillonite 
clay showed that the mineralization of the adsorbed material was much lower than what had been detected for the non-adsorbed PVOH. Similarly, Chiellini et al. [26] had found lower rates and extents of PVOH mineralization in solid cultures in the presence of either soil or compost samples. Different hypotheses were suggested to account for these observations, such as the absence or scarce occurrence of PVOH-degrading microorganisms in soil and compost matrices, the physical state of the PVOH samples, and PVOH's strong interactions with the solid matrices (Chiellini et al. [19]).

Data about adsorption of detergent film grade $\mathrm{PVOH}$ to activated sludge are not available. QSAR modelling (EPI Suite, US EPA [32]) indicates that PVOH has a very low predicted hydrophobicity (e.g. calculated $\log K_{o w}=-20$ for $\mathrm{DP}=50$ and $\mathrm{DH}=85 \%$; further decreasing by approximately 5 for every increase of DP by 10 units) and consequently a very low tendency to adsorb to organic carbon, and to activated sludge, is predicted. Thus, the main fate pathway is expected to be aquatic/dissolved.

Meier et al. [33] report on a detergent case study, where the OECD 302 test was applied to assess the inherent biodegradability of a $\mathrm{PVOH}$ based film material. In this study, $85 \%$ of the dissolved organic carbon (DOC) was removed within 4 weeks. A parallel study demonstrated that $78 \%$ of the test material's carbon had been converted to $\mathrm{CO}_{2}$ over a period of 2 months. These findings show that the PVOH film material can be qualified as 'inherently biodegradable' (cf. ECHA [34]). Consequently, it is not persistent and does not accumulate in aquatic environments. Nevertheless, ECHA [34] warns that positive inherent biodegradability test results in general should not be interpreted as conclusive evidence for rapid degradation in the environment.

For the environmental fate pathway of PVOH film used in detergent capsule applications, the relevant circumstances are the aquatic environment, under aerobic conditions. Indeed after use in the washing machine or dishwasher, the ingredients of detergent capsules - including the now dissolved PVOH - are discarded down the drain with the waste water. This is further conveyed via the sewer system, normally to a waste water purification facility, or worst case to an untreated discharge into surface water. Under all of these conditions, the literature shows that $\mathrm{PVOH}$ is biodegradable, and that especially the highly soluble variants of $\mathrm{PVOH}$ have the best biodegradation profile.

\section{Experimental procedure}

\subsection{Data sources}

Over the past decade, several companies (either detergent formulators or film producers) have commissioned ready biodegradation tests with PVOH film materials. For the purpose of the current analysis, data on 6 different films were available for review. These studies were conducted between 2010 and 2018. Because of confidentiality and competition law considerations, no information about the individual studies (neither on the test materials and their characteristics, nor on the individual results) can be publicly disclosed. Instead, the data were compiled confidentially by the European detergents industry association A.I.S.E., and were anonymised. In this paper an aggregation is provided of the different studies that were made available. Note that for materials where replicate test data had been shared, and/or materials that had been tested at more than one concentration, the average across replicates and test concentrations was used as a single value for the aggregation. The evolution of the biodegradation extent over time is presented as a cloud of all observation points for the different test materials, not identifying which are the actual materials tested, nor which data points belong together as part of one study.

All of the 6 tested film materials are confirmed to be (or to have been) used in the production of detergent capsules on the market. Thus, the DH and molecular weight (i.e. the DP) are representative of what is used in the market for detergent applications. These technical materials are not pure $\mathrm{PVOH}$ (i.e. a pure copolymer of vinyl alcohol and - a lower proportion of - vinyl acetate). First, the PVOH polymer backbone is typically modified to some extent, to address the unique needs of the detergent capsule application e.g. cold water solubility with appropriate kinetics (sufficiently fast but not prematurely), adequate compression resistance, and processing ability. Second, additives are likely present, e.g. plasticisers, aversive agents to prevent oral exposure. These additives may have been blended into the resin or may have been coated on the film. Across the tested materials presented in this paper, the $\mathrm{PVOH}$ polymer resin percentage in the film material ranges from $60 \%$ to $85 \%$. Consequently, the data presented herein reflect the holistic biodegradability profile of technical PVOH films (i.e. technical mixtures) as used for detergent capsule applications, rather than the biodegradability of pure $\mathrm{PVOH}$ in isolation.

\subsection{Biodegradation studies}

Different types of ready biodegradation test protocols were used across the available studies. These were all aerobic ready biodegradability screening tests. As a common principle, a solution of the test material is inoculated with a low amount of microorganisms, in the presence of mineral nutrients, but in absence of any other carbon source than the test material itself. These screening tests are intentionally conservative by design. Biodegradation will indeed only be observed in case the inoculated micro-organisms are able to source energy and carbon solely from the test material - and this in a sufficiently efficient way, to allow the exponential microbial growth that is required to establish a self-accelerating degradation of the material. As the microorganisms utilise the test material as a food source, part of it is taken up into the growing microbial biomass, and the remainder is converted into carbon dioxide, while in this process oxygen is consumed.

For 4 of the tested film materials, the OECD 301B approach was applied. In this test method, the amount of $\mathrm{CO}_{2}$ produced over time (captured and quantified using a sodium hydroxide trap) is expressed as a percentage of the theoretical maximum, based on the total organic carbon analysis of the sample. The OECD 301F test was used for one material. This study monitors the oxygen uptake of the microorganisms instead of their $\mathrm{CO}_{2}$ production. Finally, one material was tested according to OECD 310. Like under OECD $301 \mathrm{~B}, \mathrm{CO}_{2}$ production is monitored as a measure of biodegradation, but in this case via an inorganic carbon analysis of the test vessels. The OECD 301 and 310 series of ready biodegradability tests are the standard for screening purposes. These tests are generally considered to be conser- 
vative in nature. As such, ECHA considers a positive result in one of these tests to be unequivocal, not requiring further investigation of the biodegradability of the chemical or environmental effects of any transformation products [35].

Three OECD 301B studies were performed using $1 \mathrm{~L}$ treatments, dosed (in dissolved form) at $12 \mathrm{mg} \mathrm{C} / \mathrm{L}$. Freshly collected activated sludge from a primarily domestic wastewater treatment plant was used as inoculum and was added at a target concentration of $17 \mathrm{mg} / \mathrm{L}$. An electrolytic respirometer test system was used for the study. A conductivity probe immersed in $0.75 \% \mathrm{NaOH}$ was used to measure the production of $\mathrm{CO}_{2}$ and a pressure transducer monitored the decrease in pressure due to oxygen consumption. A sensor assembly charged with $\mathrm{CuSO}_{4}$ continually equalised the pressure with oxygen as it was consumed.

A fourth OECD 301B study was conducted using a $3 \mathrm{~L}$ treatment volume, with the pre-dissolved test material dosed at $10 \mathrm{mg} \mathrm{C} / \mathrm{L}$, and the domestic activated sludge inoculum was added to $30 \mathrm{mg} / \mathrm{L}$. Here the reactors were delivered $\mathrm{CO}_{2}$-free air and were allowed to vent into a $0.20 \% \mathrm{NaOH}$ scrubber solution. Each scrubber solution was analysed for Total Inorganic Carbon concentrations periodically throughout the extent of the test to determine the amounts of $\mathrm{CO}_{2}$ produced by each reactor.

In the OECD $301 \mathrm{~F}$ test, the measurement of oxygen uptake was conducted in respirometer units with piezoresistive electronic pressure sensors in the bottle tops. Each individual unit consisted of a dark glass $500 \mathrm{~mL}$ bottle, with a magnetic stirrer. As inoculum, activated sludge from a predominantly domestic sewage treatment works was used, at a concentration of $30 \mathrm{mg} / \mathrm{L}$ in the final volume. $10 \mathrm{mg} / \mathrm{L}$ of dissolved test material was dosed in each unit, and the balance of the volume (total of $432 \mathrm{~mL}$ ) was with standard mineral medium. Carbon dioxide produced by microbial respiration was absorbed by a $\mathrm{KOH}$ solution placed in a rubber sleeve in the neck of each bottle, and the oxygen taken up was measured as a decrease in pressure. The electronic controller collected the pressure values from the measuring tops and calculated the biological oxygen demand (as $\mathrm{mg} / \mathrm{L}$ ). Oxygen uptake was recorded automatically every $112 \mathrm{~min}$ during the experimental period. Oxygen uptake values were corrected for the inoculum blank, and the biodegradation was calculated as a percentage of the measured chemical oxygen demand for the test substance.

The OECD 310 test was carried out in $125 \mathrm{~mL}$ serum vessels, sealed with butyl rubber septa and aluminium crimp caps. The vessels were incubated in an incubator-shaker, shaking at $150 \mathrm{rpm}$. As inoculum, activated sludge from a predominantly domestic sewage treatment works was used, at a final sludge solids concentration of $4 \mathrm{mg} / \mathrm{L}$. The test substance vessels contained pre-dissolved $\mathrm{PVOH}$ film at nominal $5.0 \mathrm{mg} / \mathrm{L}$ or $7.5 \mathrm{mg} / \mathrm{L}$ as carbon, in standard mineral medium. The total liquid volume in the test vessels was $100 \mathrm{~mL}$. On sampling days, sacrificed vessels were made alkaline by the addition of a sodium hydroxide solution, to trap the produced $\mathrm{CO}_{2}$. Samples taken from the liquid were then analysed for inorganic carbon. Mineralization of the test and reference materials was followed by measurement of carbon dioxide evolution on days 4, 7, and subsequent 7-day intervals. Biodegradation was calculated as the ratio of evolved inorganic carbon to the (measured) organic carbon added at the start of the study.
All of the above studies covered a 28-day test period. In addition, three studies were continued beyond this point, up to 60 days according to the REACH PBT enhanced ready biodegradation approach [35].

The above test protocols are biologically equivalent, despite differences in terms of execution and measured parameters. Importantly, the test material and inoculum concentrations are similar and in all methods the inoculum is from (predominantly) domestic activated sludge sewage treatment plants. None of the studies used pre-acclimated inoculum. Whether biodegradation activity is measured either via $\mathrm{CO}_{2}$ production (OECD 301B) or via $\mathrm{O}_{2}$ consumption (OECD 301F and OECD 310) is biologically inconsequential, because both are metrics (respectively output and input) of the same processes. As a reference value, in each of these methods a hypothetical maximum (100\%) is determined based on the assumed full decomposition of the test material. The pass level for biodegradability is the same for the three test methods, i.e. $60 \%$ of the hypothetical maximum. Whereas the protocol differences may impact especially the start-up phase of the biodegradation studies (length of the lag phase, initial kinetics), the eventual outcome once the bacteria have achieved exponential growth is not expected to be fundamentally different. Consequently, for the purpose of the current assessment it was deemed appropriate to aggregate the results from OECD 301B, 301F and 310 studies into a single overview. To ensure confidentiality, only the first 28 days of all studies were included in the aggregation.

\subsection{Interpretation}

To help interpret the aggregated data set, mathematical modelling was applied. The logistic plot is generally used to estimate the rate constant for biodegradation and is applicable for sigmoidal degradation curves (Reuschenbach et al. [36]). The following equation (Larson et al. [37]) for the logistic model describes an S-shaped degradation curve in singledose batch systems:

$y=a \cdot\left(1-\mathrm{e}^{-k_{1} \cdot t}\right)^{-1 / n}$

where $y=$ cumulative percentage of biodegradation (\%)

$t=$ time (days)

$a=$ asymptotic value for the cumulative percentage of biodegradation (\%)

$k_{1}=$ first-order biodegradation rate constant $\left(\right.$ day $\left.^{-1}\right)$

$n=$ empirical constant

This model was fitted to the data by means of numerical optimisation (Excel for Mac 2011, version 14.4.1, Solver GLG Non-linear engine). For each observed data point, the residual between the measured and modelled cumulative biodegradation percentages was calculated. Next, for each of the six different studies, the sum of the squared residuals across the data points in that study was determined. These sum of squares values for each individual study were then divided by the number of data points in that specific study - to ensure an equal weight for each of the studies (as without this last step, a higher weight would implicitly be given to studies with more data points). Finally, the overall sum of these metrics was calculated across the six studies. This overall sum was minimised by means of numerical optimisation of the three model parameters $\left(a, k_{1}\right.$ and $\left.n\right)$. 


\section{Results and discussion}

Each of the six materials in the data set exhibited a degradation profile that followed a sigmoidal pattern. The aggregated data (up to 28 days) are presented in Figure 5, accompanied by the fitted logistic model curve. For 3 of the tested materials, data were collected up to 60 days, however, this cannot be included in the chart to avoid confidentiality concerns (i.e. it shall not be possible to identify individual materials).

The extent of biodegradation after 28 days was $60.4 \%$ on average across the six materials. Across the studies, the 28 days value ranged quite broadly, from $38 \%$ up to $86 \%$. As outlined above, different study protocols had been used, that are fundamentally equivalent but that nevertheless could result in a different duration of the lag phase or different kinetics. As such, the relevant result to be compared across the studies is the eventual biodegradation percentage, rather than what happens during the first weeks of the study. For 2 out of the 6 materials, the $60 \%$ threshold was not reached within 28 days. However, for these specific film materials, the enhanced OECD 301B protocol had been applied with measurements continuing up to 60 days. This showed a biodegradation extent well above the $60 \%$ threshold in both cases, demonstrating that the result below $60 \%$ on day 28 did not imply a lack of biodegradability.

The fitted logistic model has the following parameters: $a=97.7 \%, k_{1}=0.0567$ day $^{-1}, n=-0.483$. The model calculation of the biodegradation extent at 28 days $(60.8 \%)$ closely matches the average of the observed data $(60.4 \%)$. The high asymptotic value $a$ confirms the ongoing integral biodegradation, going well beyond the $60 \%$ threshold over time.

All of the studies exhibited an initial lag phase, before the biodegradation process self-accelerated. The duration of the lag phase varied between the studies. This may potentially be explained by the fact that the test materials are complex mixtures, with varying auxiliary ingredients in addition to $\mathrm{PVOH}$, and also by the fact that PVOH itself is a polydisperse material. But also differences in the adaptation to $\mathrm{PVOH}$ of the inoculum (domestic activated sludge) may have been a factor, especially in the older studies that were conducted at a time when detergent capsules did not yet have a broad market presence. The importance of adaptation for the biodegradation of $\mathrm{PVOH}$ has been well established in the literature $[18,19,27,28]$.
Note that the 10-day window concept is not relevant in the context of films because these are mixtures, not single substances. For perspective, the European Commission Scientific Committee on Toxicity, Ecotoxicity and the Environment deemed it not necessary to utilise the 10-day window criteria for assessing the ultimate biodegradability of surfactants in detergents - due to the different kinetics associated with different homologues present in many commercial surfactants [38]. Finally, the 10-day window is not relevant for a microplastics assessment, of which the main focus is absence of persistence, rather than the actual rate of biodegradation.

Extrapolating the fitted logistic model further in time (Figure 6) predicts the ultimate complete biodegradability of the PVOH films in this assessment.

The presented data confirm that the PVOH material used in detergent capsule film materials is biodegradable. As this was shown by means of the stringent OECD ready biodegradability screening tests, due to the conservative design of the studies, these positive results unequivocally indicate rapid and ultimate biodegradation in most environments (ECHA [35]). These findings are in line with what is reported in the literature on PVOH (e.g. [17, 19]) and on PVOH based detergent film [33].

The positive results in the screening biodegradation tests are not per se conflicting with literature that concluded poor biodegradability for $\mathrm{PVOH}[18]$, or that detected $\mathrm{PVOH}$ in environmental samples [5-8]. This is because a very broad range of applications for $\mathrm{PVOH}$ exist [11-15], each with specific requirements for the physical/chemical properties. These different properties are achieved via different polymer design strategies. Not all PVOH is equally water soluble, and neither is it equally biodegradable. Complete water solubility, also at low temperatures, is a prerequisite for detergent capsule film applications. And as Chiellini et al. [24] pointed out, in the aquatic environment (which is the relevant pathway for down-the-drain detergent products), high water solubility of $\mathrm{PVOH}$ is correlated with biodegradability. However, several $\mathrm{PVOH}$ applications outside of the detergents sector, with lower water solubility, may indeed exhibit a less favourable biodegradation profile.

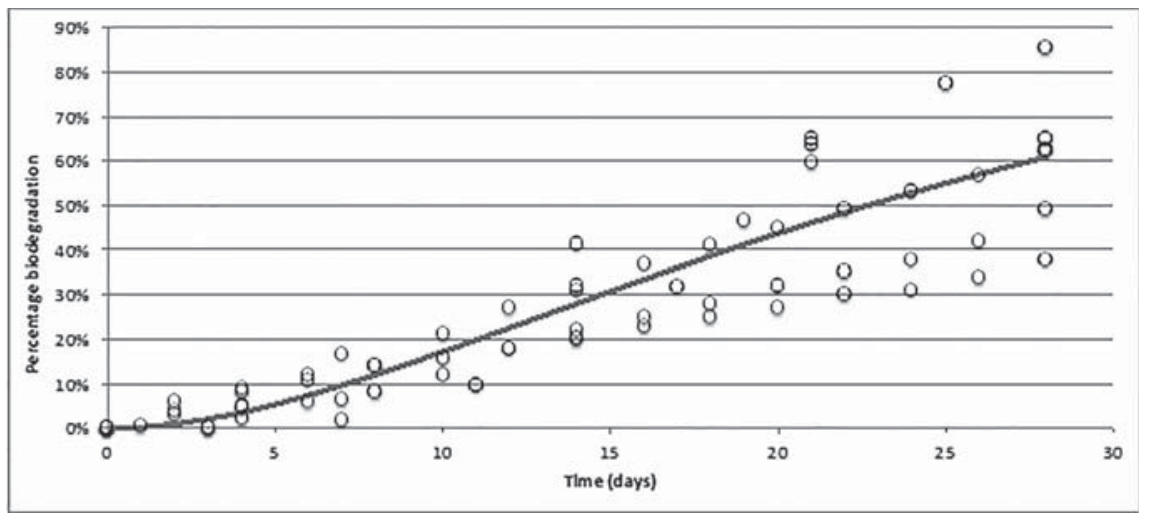

Figure 5 Biodegradation of PVOH films - aggregation of observed biodegradation data up to 28 days (circles) and the fitted logistic model (line) 


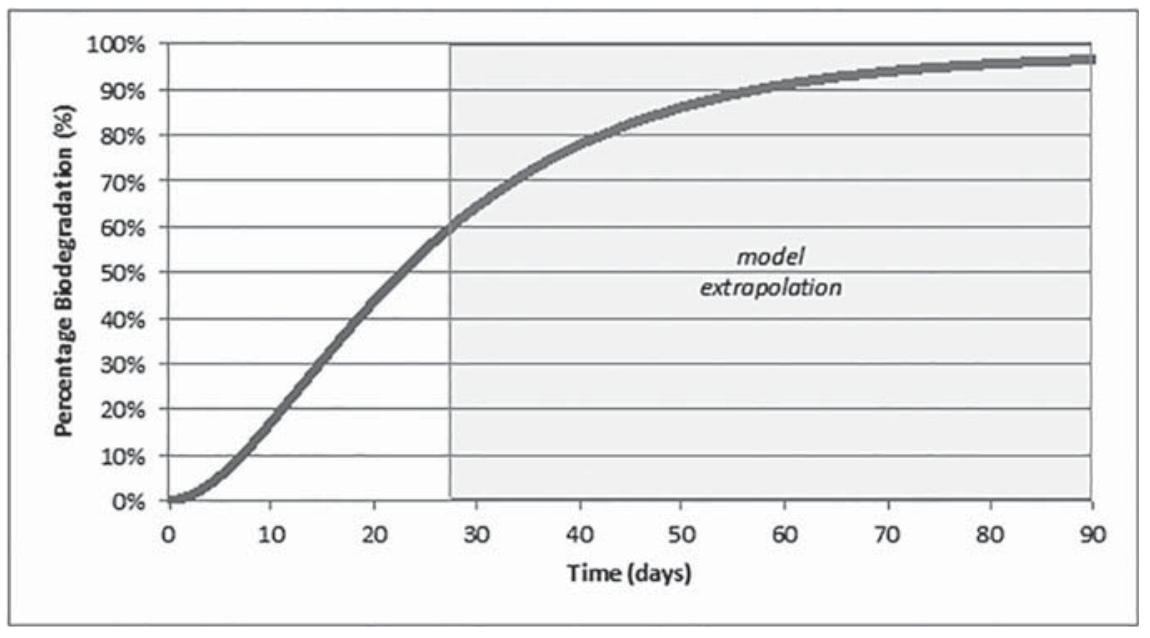

Figure 6 Biodegradation of PVOH films - model extrapolation beyond 28 days

\section{Conclusions}

Due to its structural similarity to biological materials such as cellulose, PVOH has the potential for complete biodegradation, especially PVOH grades that are highly water-soluble. As PVOH has a very broad diversity of applications, this unique class of polymers covers a large range of polymer chemistry and chain architecture (e.g. DH and DP, but also polymer backbone modifications). Within this range, the narrower subset of PVOH materials that is suitable for use as soluble film for detergent capsules, meets the criteria for biodegradability.

Ready biodegradability screening test data on six technical (commercial) PVOH film materials were confidentially collected, anonymised and aggregated for the current assessment. These materials represent a range of actual PVOH films, including structural modifications and added auxiliary ingredients, formulated to meet the performance and safety requirements for this specific detergents market. Substantial variability was seen between the results of biodegradation studies on different films. This includes differences in the length of the lag phase, the rate of biodegradation during the exponential phase, and the extent reached after 28 days. Some materials met the full ready biodegradation criteria. Some other materials underwent biodegradation at a lower rate and did not reach $60 \%$ biodegradation after 28 days. Nevertheless, for these materials the biodegradation process had continued and this threshold was well exceeded later on in the enhanced part of the biodegradation test (running for an additional 32 days). Modelling across all aggregated data, a total extent of biodegradation of $60 \%$ was reached after 28 days. The 10-day window is irrelevant due to the fact that the films are chemical mixtures, and because it has no relevance for the microplastic assessment.

The ready biodegradability data on $\mathrm{PVOH}$ films used for detergent applications, as collected and aggregated herein, confirm the information in the literature that highly soluble $\mathrm{PVOH}$ biodegrades in an aqueous environment. Addressing the main question of the current paper, PVOH film of detergent capsules was shown to be biodegradable in OECD screening test conditions. Despite variable biodegradation rates between studies and materials, all films were found to meet the criteria for biodegradability in these stringent stud- ies - which offers definitive and conclusive evidence of their actual biodegradability in the environment.

In conclusion, PVOH used in liquid detergent capsule films does not meet any of the definitions of microplastic: (1) it is not micro- or nano-sized; (2) it is highly water-soluble; and (3) it is biodegradable in the environmental conditions where it is discharged.

\section{References}

1. ECHA: ANNEX XV RESTRICTION REPORT. Proposal for a restriction. Substance name(s): intentionally added microplastics. 22 August 2019. European Chemicals Agency, Helsinki, Finland; https://echa.europa.eu/documents/10162/ 05bd96e3-b969-0a7c-c6do-441182893720.

2. EU Commission: Request to the European Chemicals Agency to prepare a restriction proposal conforming to the requirements of Annex XV to REACH. 2017; https://echa.europa.eu/documents/10162/13641/microplastics_cion_ reqst_axvdossier_en.pdf/5c8be037-3f81-266a-d71b-1a67ec01 cbf $\overline{9}$.

3. $E C H \bar{A} R A C$ : Opinion of the Committee for Risk Assessment and Opinion of the Committee for Socio-economic Analysis on an Annex XV dossier proposing restrictions of the manufacture, placing on the market or use of a substance within the EU. 11 June 2020. European Chemicals Agency, Helsinki, Finland; https://echa.europa.eu/documents/10162/23665416/rest_microplastics_ opinion rac 16339 en.pdf/b4d383cd-24fc-82e9-cccf-6d9f66ee9089.

4. Thompson, $\bar{A}$.: From Fish to Humans, A Microplastic Invasion May Be Taking a Toll. www.scientificamerican.com September 4, 2018.

5. GESAMP: Sources, fate and effects of microplastics in the marine environment: a global assessment (Kershaw, P. J., ed.). (IMO/FAO/UNESCO-IOC/UNIDO/ WMO/IAEA/UN/UNEP/UNDP Joint Group of Experts on the Scientific Aspects of Marine Environmental Protection). Rep. Stud. GESAMP No. 90, 96 p, 2015.

6. Hidalgo-Ruz, V., Gutow, L., Thompson, R. C. and Thiel, M.: Microplastics in the Marine Environment: A Review of the Methods Used for Identification and Quantification. Environmental Science \& Technology, 46(6)(2012). pp 30603075;. PMid:22321064; DOI:10.1021/es2031505

7. Vianello, A., Boldrin, A., Guerriero, P., Moschino, V., Rella, R., Sturaro, A. and Da Ros, L.: Microplastic particles in sediments of Lagoon of Venice, Italy: First observations on occurrence, spatial patterns and identification. Estuarine, Coastal and Shelf Science 130 (2013) 54-61. DOI:10.1016/j.ecss.2013.03.022

8. Claessens, M., De Meester, S., Van Landuyt, L., De Clerck, K. and Janssen, C. R.: Occurrence and distribution of microplastics in marine sediments along the Belgian coast. Marine Pollution Bulletin, 62(10) (2011). pp 2199-2204. PMid:21802098; DOI:10.1016/.jmarpolbul.2011.06.030

9. ASTM: Standard Safety Specification for Liquid Laundry Packets, ASTM F315915e1, ASTM International, West Conshohocken, PA, 2015, www.astm.org.

10. Finch, C. A. (Ed.): Polyvinyl alcohol, properties and applications. Wiley, New York, 1973. 622 pp. DOl:10.1002/pol.1974.130120212

11. Grand View Research: Polyvinyl Alcohol (PVA) Market Size, Share \& Trends Analysis Report By End Use (Paper, Food Packaging, Construction, Electronics), By Region, And Segment Forecasts, 2019-2025. (2019) https://www.grandviewresearch.com/industry-analysis/polyvinyl-alcohol-market.

12. Thong, C. C., Teo, D. C. L. and Ng, C. K.: Application of polyvinyl alcohol (PVA) in cement-based composite materials: A review of its engineering properties and microstructure behavior. Construction and Building Materials 107 (2016), 172 - 180. DOI:10.1016/j.conbuildmat.2015.12.188 
13. Muppalaneni, S. and Omidian, H.: Polyvinyl Alcohol in Medicine and Pharmacy: A Perspective. J Develop Drugs 2 (2013) 112. DOI:10.4172/2329-6631.1000112

14. Gaaz, T. S., Sulong, A. B., Akhtar, M. N., Kadhum, A. A. H., Mohamad, A.B. and Al-Amiery A.A.: Properties and Applications of Polyvinyl Alcohol, Halloysite Nanotubes and their nanocomposites. Molecules 20 (2015), 22833-22847. PMid:26703542; DOI:10.3390/molecules201219884

15. American Carp Society: The use of PVA in carp angling (2019). https://americancarpsociety.com/pva-bags.

16. Monosol: Water soluble film, packets employing the film, and methods of making and using same. World Intellectual Property Organisation, publication nr WO 2016/160116 A1 (2016).

17. Amann, M. and Minge, O.: Biodegradability of Poly(vinyl acetate) and Related Polymers. Advances in Polymer Science 245 (2012) 137- 172. DOI:10.1007/12_2011_153

18. Julinová, M., Vaňhharová, L. and Jurc?a, M.: Water-soluble polymeric xenobiotics - Polyvinyl alcohol and polyvinylpyrrolidon - And potential solutions to environmental issues: A brief review. Journal of Environmental Management 228 (2018) 213-222. PMid:30223180; DOI:10.1016/j.jenvman.2018.09.010

19. Chiellini, E., Corti, A., D'Antone, S. and Solaro, R.: Biodegradation of poly (vinyl alcohol) based materials. Progress in Polymer Science 28(6) (2003), 963 1014. DOI:10.1016/S0079-6700(02)00149-1

20. Kawai, F. and $H u, X$ : Biochemistry of microbial polyvinyl alcohol degradation. Applied Microbiology and Biotechnology 84(2) (2009), 227-237. PMid: 19590867: DOI: 10.1007/s00253-009-2113-6

21. Solaro, $R$, Corti, $A$ and Chiellini, E. Biodegradation of poly(vinyl alcohol) with different molecular weights and degree of hydrolysis. Polym Adv Technol 11 (2000):873-878. DOI:10.1002/1099-1581(200008/12) $11: 8 / 12<873:: A I D-P A T 35>3.0 . C O ; 2-V$

22. Yamatsu, A., Matsumi, R., Atomi, H. and Imanaka, T.: Isolation and characterization of a novel poly(vinylalcohol)-degrading bacterium, Sphingopyxis sp. PVA3. Appl Microbiol Biotechnol 72 (2006), 804-81. PMid:16583228; DOI: 10.1007/s00253-006-0351-4

23. Wilkes, R. A. and Aristilde, L.: Degradation and Metabolism of Synthetic Plastics and Associated Products by Pseudomonas spp.: Capabilities and Challenges. Journal of Applied Microbiology 123(3) (2017), 582 - 593. PMid:28419654 DOI: $10.1111 / j a m .13472$

24. Chiellini, E., Corti, A., Del Sarto, G. and D'Antone, S.: Oxo-biodegradable polymers - effect of hydrolysis degree on biodegradation behaviour of poly(vinyl alcohol). Polym. Degrad. Stab. 91 (2006), 3397-3406. DOI:10.1016/j.polymdegradstab.2006.05.021

25. Hatanaka, T., Asahi, N. and Tsuji, M.: Purification and characterization of a poly(vinyl alcohol) dehydrogenase from Pseudomonas sp. 113P3. Biosci. Biotechnol. Biochem. 59 (1995), 1813 - 1816. DOI:10.1271/bbb.59.1813

26. Chiellini, E., Corti, A. and Solaro, R.: Biodegradation of poly(vinyl alcohol) based blown films under different environmental conditions. Polymer Degradation and Stability 64(2) (1999), 305-312. DOI:10.1016/S0141-3910(98)00206-7

27. Pajak, J., Ziemski, M. and Nowak, B.: Poly(vinyl alcohol) - biodegradable vinyl material. Chemik 64 (2010), 523-530.

28. OECD: Guideline for testing of chemicals 302B. Zahn-Wellens/EMPA Test. July 1992. DOI: 10.1787/9789264070387-en

29. Matsumura, S., Kurita, H. and Shimokobe, H.: Anaerobic biodegradability of polyvinyl alcohol. Biotechnol. Lett. 15(7) (1993), 749-754. DOI:10.1007/BF01080150

30. Marušincová, H., Husárová, L., R?žička, J., Ingr, M., Navrátil, V., Buňková, L. and Koutny, M.: Polyvinyl alcohol biodegradation under denitrifying conditions. International Biodeterioration \& Biodegradation 84(2013), 21 - 28 DOI: 10.1007/BF01080150

31. Chiellini, E., Corti, A., Politi, B. and Solaro, R.: Adsorption/Desorption of Polyvinyl Alcohol on Solid Substrates and Relevant Biodegradation. Journal of Polymers and the Environment (2000) 8,67-79.

DOI:10.1023/A: 1011569920349
32. US EPA: Estimation Programs Interface Suite ${ }^{T M}$ for Microsoft ${ }^{\circledR}$ Windows, v 4.11, 2012. United States Environmental Protection Agency, Washington, DC, USA.

33. Meier F Stelter $N$ Lee D. M Zeese $N$ J and Tolls, J. Raw material supplier and detergent manufacturer cooperate in environmental safety assessment of a new detergent raw material - a case study. SOFW Journal 139(3) (2013), 58-62.

34. ECHA: Guidance on the Application of the CLP Criteria. Guidance to Regulation (EC) No 1272/2008 on classification, labelling and packaging (CLP) of substances and mixtures. Version 5.0 July 2017. European Chemicals Agency, Helsinki, Finland. DOI:10.2823/124801

35. ECHA: Guidance on information requirements and chemical safety assessment. Chapter r.7b: Endpoint specific guidance. Version 4.0 June 2017. European Chemicals Agency, Helsinki, Finland; https://doi.org/10.2823/84188.

36. Reuschenbach, P., Pagga, U. and Strotmann, U.: A critical comparison of respirometric biodegradation tests based on OECD 301 and related test methods. Water Res. 37(2003), $1571-1582$. DOI:10.1016/S0043-1354(02)00528-6

37. Larson, R. J., Hansmann, M. A. and Bookland, E. A.: Carbon oxide recovery in ready biodegradation tests: mass transfer and kinetic consideration. Chemosphere 33(1996), 1195-1210. DOI:10.1016/0045-6535(96)00253-6

38. CSTEE: Proposed "ready biodegradability" approach to update detergents legislation. E. A. T. E. C. Scientific Committee On Toxicity, 1999.

Received: 04.11.2020

Accepted: 16.12.2020

\section{Bibliography}

DOI 10.1515/tsd-2020-2326

Tenside Surf. Det. 58 (2021) 2, page 88-96

(c) 2021 Walter de Gruyter GmbH, Berlin/Boston, Germany

ISSN 0932-3414 · e-ISSN 2195-8564

\section{Correspondence address}

\section{Mr Dominic Byrne}

A.I.S.E. - The International Association for Soaps,

Detergents and Maintenance Products

Boulevard du Souverain 165 - 4th floor

1160 Brussels

Belgium

Tel.: +32 (0)2 6796268

Fax: +32 (0)2 6796279

E-Mail: dominic.byrne@aise.eu

\section{The author of this paper}

Dominic Byrne is a scientific and regulatory affairs expert specialising in European chemical control regulation, specifically the REACH and CLP Regulations. His scientific areas of expertise include substance identification and determining the physicochemical properties of chemical substances and mixtures. In 2012 he earned an Honours Bachelors Degree in Chemistry from University College Dublin. Subsequently, he has worked for the European Chemicals Agency, Blue Frog Scientific and A.I.S.E. - The International Association for Soaps, Detergents and Maintenance Products. 